
\title{
28 Research Square \\ Predicting the impacts of land management for sustainable development on depression risk in a Ugandan case study
}

Thomas Pienkowski ( $\nabla$ thomas.pienkowski@zoo.ox.ac.uk)

University of Oxford

\section{Aidan Keane}

University of Edinburgh

Eugene Kinyanda

Medical Research Council/Uganda Virus Research Institute and London School of Hygiene \& Tropical Medicine Uganda Research Unit

\section{Caroline Asiimwe}

Budongo Conservation Field Station

\section{E.J. Milner-Gulland}

University of Oxford

\section{Research Article}

Keywords: Agricultural intensification, Biodiversity conservation, Budongo, Common mental disorder, Contract farming, Mental health, Predictive conservation, Predictive landscape planning, Scenario analysis, Sustainable development goal

Posted Date: November 10th, 2021

DOI: https://doi.org/10.21203/rs.3.rs-1064228/v1

License: (c) (1) This work is licensed under a Creative Commons Attribution 4.0 International License. Read Full License 


\section{Abstract}

Agricultural intensification and expanding protected areas are proposed sustainable development approaches. But, their consequences for mental health - a global priority - are poorly understood. We predict how forest conservation and contract farming may alter resource access and depression risk in rural Uganda. We asked 695 residents in 11 communities about their expectations under land management scenarios, household characteristics, and depression symptoms. Over $80 \%$ of respondents presented with a 'business-as-usual forest-access' scenario expected reduced forest income and food over the next decade. This number climbed to over $90 \%$ among respondents presented with a 'restricted forest access' scenario. Over $80 \%$ said losing forest access would increase food insecurity and poverty among forest-dependent households. Furthermore, over $99 \%$ of those presented with two land access scenarios ('business-as-usual land access' and 'sugarcane expansion land access') expected wealthy households to gain land but poorer families to lose it. This land redistribution was expected to increase poverty and food insecurity among small-scale farmers. Bayesian structural equation suggested that depression severity was positively associated with food insecurity (estimate $=0.20,95 \% \mathrm{Cl}=0.12-0.28$ ) and economic poverty (estimate $=0.11,95 \% \mathrm{Cl} 0.02-0.19$ ). Conservation and agricultural approaches that restrict access to livelihood resources may threaten vulnerable groups' mental health.

\section{Introduction}

Humanity faces the joint challenge of reversing the loss of nature whilst supporting human health and wellbeing. Two intersecting global policy frameworks seek to address this challenge. The proposed post2020 global biodiversity framework aims to catalyse "urgent action across society to put biodiversity on a path to recovery for the benefit of planet and people" as a step towards living in harmony with nature by 2050 ${ }^{1}$. Simultaneously, the 17 United Nations 2030 Sustainable Development Goals (SDG) include ending poverty (SDG 1) and hunger (SDG 2) while reducing inequalities (SDG 10) and ensuring health for all $(\text { SDG 3) })^{2}$.

How landscapes are managed will play a key role in addressing this joint challenge in the coming decades. For example, feeding the world's population whilst protecting nature will require significant changes in how agroecological systems are organised ${ }^{3}$. Often, land management interventions change who has access to nature, with complex trade-offs and co-benefits in relation to multiple dimensions of wellbeing 4,5 . A core part of wellbeing is mental health, defined as the capacity of thoughts, emotions, and behaviours that enable people to realise their potential, cope with stresses, work productively, and contribute to their community 6,7 . Yet, evidence of how land management can influence access nature in ways that affect mental health - an emerging global priority 7,8 - is patchy ${ }^{9}$.

This patchy understanding has several implications. First, there may be hidden trade-offs between mental health and other sustainable development targets that are poorly accounted for when designing land management policy. For instance, some land management approaches that seek to protect nature (SDG 15) could alter access to natural resources in ways that undermine progress to mental health targets 
(SDG Target 3.4 $)^{9}$. Second, understanding these connections may reveal land management approaches that simultaneously contribute to mental health and other sustainable development objectives. For example, given the strong links between poverty and mental illness ${ }^{10}$, land management policies that promote sustainable natural resource use could support mental health. Anticipating these trade-offs and co-benefits could help decision-makers choose land management approaches that promote mental health within a functional and diverse biosphere ${ }^{11}$.

This article aims to predict how land management for sustainable development could alter access to nature in ways that affect mental health. Specifically, we explore how agricultural intensification and restrictive protected areas may increase depression risk through a Ugandan case study. In doing so, we encourage policymakers to anticipate how land management approaches could alter access to nature in ways that either undermine or support mental health goals.

\section{Natures contributions and mental illness}

In the following, we illustrate how access to nature can influence social determinants of mental health (Figure 1). We do so by drawing on three bodies of evidence. First, mental illness is defined as a disturbance of "thought, emotion, behaviour, and relationships with others that lead to substantial suffering and functional impairment" in major life activities ${ }^{7}$. Much of the burden of mental illness is attributed to common mental disorders, including depression, anxiety, and post-traumatic stress. Common mental disorders are a leading threat to wellbeing and contributor to the global burden of disease $^{12}$. For instance, mental disorders contributed around $35 \%$ of total years lived with disability in 2015 , and over 260 million people were estimated to have had depression in $2017^{13,14}$. Multiple factors influence an individual's risk of mental illness, including the interaction of psychobiological vulnerabilities and external stressors ${ }^{7}$. These stressors can emerge from the economic, social, cultural, demographic, and environmental context of people's lives, termed social determinants within public health literature ${ }^{10}$. For instance, poverty is a recognised social determinant of mental illness ${ }^{10,15-17}$. Many of these social determinants might be influenced by interactions with the natural world.

Second, nature refers to the natural world, with an emphasis on biodiversity ${ }^{18}$ (the variability of life on earth ${ }^{19}$ ). In our study, both land and forests are considered part of nature. The interaction of nature and human assets (like infrastructure, technology, or financial capital) co-produce food, energy sources, materials, materials, medicine, and other contributions to human wellbeing ${ }^{18}$. These are termed nature's contributions to people ${ }^{20}$. For example, wild foods harvested from nature support dietary diversity and good nutrition in many parts of the world ${ }^{21}$. Therefore, the interactions between human assets and nature may alter social determinants of mental illness. For instance, forest resources can contribute to food security, a known social determinant of common mental disorders ${ }^{10,21}$.

Finally, access has been defined as the "ability to benefit from things" 22 . An individual or group's ability to access something can be determined by the rights, knowledge, authority, social relations, markets, and 
other factors available to them ${ }^{22}$. Access often mediates relationships between nature and people's wellbeing ${ }^{23-25}$ and can be determined by formal and informal institutions and governance systems ${ }^{20}$. For instance, Thoms ${ }^{26}$ describe how elites within community forestry groups in Nepal restricted access to forests, harming the livelihoods of poorer households. Therefore, access is a crucial factor determining who can co-produce and benefit from nature's contributions ${ }^{20}$. Furthermore, multiple factors can change patterns of resource access, including land management policies and practices. For example, recent "land grabs" driven by agricultural modernisation, conservation, urbanisation, and other pressures have changed who has access to land in many parts of the world ${ }^{27}$. A wide range of actors can influence land management ${ }^{28}$. However, we are principally interested in how local and national governments control and incentivise land management practices. We explore how two landscape management approaches for sustainable development - agricultural intensification through contract farming and protected areas alter patterns of access to land and forests.

Protected areas cover $15 \%$ of the world's land area and range from categories that permit sustainable use to those strictly limiting public access ${ }^{29}$. Residents can face a wide range of benefits and costs from living next to protected areas, which can be highly contextual and differentiated between groups ${ }^{30}$. Protected areas are a critical approach within the post-2020 global biodiversity framework, with plans to double their current extent by $2030^{1,29}$. This expansion is expected to affect the lives of hundreds of millions of people ${ }^{31}$, including changing patterns of access to nature. While the social impacts of this expansion might vary between contexts, there are widespread concerns about its impact on Indigenous groups and other residents ${ }^{32}$.

Like protected areas, agriculture is a globally prevalent land use, covering $37 \%$ of the world's land surface $^{33}$. Contract farming has been promoted as a tool for sustainable development, offering the potential to increase food production, agricultural incomes, and employment while limiting nature loss ${ }^{34}$. Contract farming is where a processor agrees to purchase agricultural commodities from smallholder farmers under contract. Contracts can reduce farmers' uncertainty about returns on investment and the transaction cost of finding buyers while improving access to inputs, finance, and extension services ${ }^{35}$. However, the distribution of benefits and costs of contract farming partly depends on who can engage in it and how it changes access to resources like land ${ }^{36}$. For instance, the expansion of contract farming had complex and differentiated social impacts in parts of Ghana, Kenya and Zambia, but resulted in the consolidation of land by elites in several cases ${ }^{37}$. As such, the ability of contract farming to promote equitable sustainable development partly depends on how inclusive it is ${ }^{34}$.

Our case study predicts how stricter protection of forests and the expansion of contract farming might alter access to nature and its contributions to social determinates of depression. We focus on these land uses because they are globally prevalent, closely linked to rural livelihoods, and likely to play central roles in efforts to meet global sustainability targets ${ }^{3}$. We use scenario-based interviews as a predictive approach that can provide evidence of credible outcomes associated with potential intervention ${ }^{38}$. 
Scenario-based interviews can leverage local expertise to explore how and why people might behave under plausible future scenarios ${ }^{38}$. For example, Cinner, et al. ${ }^{39}$ conducted scenario-based interviews with Tanzanian fishers, with many saying they would increase their fishing effort if catches declined. In addition, scenario-based interviews can be combined with other methods to provide nuanced predictions of future outcomes. We, therefore, combine interviews with a Bayesian structural equation model analysis, modelling pathways between nature use and depressive symptom severity. This combined approach illustrates how future land management may change access to forest and land (Component 1) in ways that influence social determinants of depression (Component 2 ) among communities around Budongo Forest in Masindi District, western Uganda. Component 1 explores how land management could influence access to land and forests, and in turn food and income, through hypothetical scenarios. In this Component, we ask two research questions:

- RQ1: What are the perceived impacts of restricted forest access on food security and economic poverty among forest-using households compared to business-as-usual (BAU) over the next decade?

- RQ2: What are the perceived impacts of an expansion of contract farming on land distribution, food security, and economic poverty compared to BAU over the next decade?

Component 2 empirically models relationships between indicators of land and forest use, poverty and food security, and depression risk (Figure 2). Here, we hypothesise that:

- H1: Forest use is positively associated with economic poverty and food insecurity.

- H2: Farm size is negatively associated with poverty and food insecurity.

- H3: Food insecurity and economic poverty are positively correlated with depressive symptom severity, controlling for covariates.

\section{Methods}

\section{Target population and sampling strategy}

This study builds on the findings of previous qualitative research in the same study site around Budongo Forest (Figure 3, Supplementary methods (SM) 1: Study site description) ${ }^{9}$. The target population includes male and female household heads (aged 18 to 60 ) of small-scale subsistence and contract farming households in 11 communities in Nyabyeya and Kabango parishes. The research team systematically sampled this population by walking through communities, sampling every third household, excluding non-farming households. Respondents were surveyed in English, Kiswahili and Runyoro languages from March to May 2021.

\section{Ethical approval}

was granted by the Uganda National Council of Science and Technology (Ref. SS6007) of the Government of Uganda and an Ethical Review Board at the University of Oxford, United Kingdom (Ref. 
R63458/ RE002). The study followed the approved ethical protocol, which included gaining the informed consent of participants, following United Kingdom and Ugandan government COVID-19 safety guidelines, and other procedures.

\section{Component 1: Hypothetical landscape management scenarios}

Many residents have witnessed changing forest and land access and management ${ }^{9}$. As such, the study participants were considered well-positioned to predict how hypothetical landscape management scenarios might affect their lives. Each respondent was randomly assigned a set of questions corresponding to one of four hypothetical scenarios (Table 1). One pair of scenarios included questions about the expected changes in the amount of food and income-generating 'things' that households would get from the forest in the next ten years. This pair contrasted a BAU scenario against one in which access to forests was restricted. The second pair of scenarios explored expected changes in who has access to land over the next ten years. In this second pair, a BAU scenario was contrasted against one in which government policies increased sugarcane prices, incentivising expansion of contract farming. These scenarios were designed to reflect plausible land management approaches, informed by previous research in the study site ${ }^{9}$, that the Ugandan government might take to meet conservation and sustainable development targets. For instance, the Ugandan National Development Plan 2020/21$2024 / 25$ aims to raise farmers' incomes by increasing land productivity ${ }^{42}$. Contract farming is likely to continue to be promoted as a tool to reach this goal. The BAU scenarios explore residents' expectations about the future, where no hypothetical interventions were presented. 
Table 1

Four scenarios were presented to respondents, contrasting business-as-usual (BAU) scenarios against hypothetical changes in land management. Each respondent was randomly assigned one scenario.

\begin{tabular}{|c|c|c|}
\hline & Business-as-usual & Hypothetical intervention \\
\hline \multirow[t]{2}{*}{$\begin{array}{l}\text { Forest } \\
\text { access }\end{array}$} & $\begin{array}{l}\text { BAU forest access: "Some } \\
\text { households in this community get } \\
\text { food from the forest, like herbs, } \\
\text { animals and mushrooms. In the } \\
\text { next ten years, do you think } \\
\text { households will get less food } \\
\text { from the forest, more food from } \\
\text { the forest, or will there be no } \\
\text { change?" }\end{array}$ & $\begin{array}{l}\text { Restricted forest access: "Some households in this } \\
\text { community get food from the forest, like herbs, } \\
\text { animals and mushrooms. I want you to imagine that } \\
\text { people were not allowed to get anything from the } \\
\text { forest, and there were more guards in the forest, over } \\
\text { the next ten years. When you imagine this, do you } \\
\text { think households would get less food from the forest, } \\
\text { more food from the forest, or would there be no } \\
\text { change?" }\end{array}$ \\
\hline & $\begin{array}{l}\text { "Some households in this } \\
\text { community get things from the } \\
\text { forest to make money, like selling } \\
\text { firewood, timber, and charcoal. In } \\
\text { the next ten years, do you think } \\
\text { households will get fewer things } \\
\text { from the forest to make money, } \\
\text { more things from the forest to } \\
\text { make money, or will there be no } \\
\text { change?" }\end{array}$ & $\begin{array}{l}\text { "Some households in this community get things from } \\
\text { the forest to make money, like selling firewood, timber, } \\
\text { and charcoal. I want you to still imagine that people } \\
\text { were not allowed to get anything from the forest, and } \\
\text { there were more guards in the forest, over the next ten } \\
\text { years. When you imagine this, do you think people } \\
\text { would get fewer things from the forest to make } \\
\text { money, more things from the forest to make money, } \\
\text { or would there be no change?" }\end{array}$ \\
\hline $\begin{array}{l}\text { Land } \\
\text { access }\end{array}$ & $\begin{array}{l}\text { BAU land access: "Do you think } \\
\text { there will be a change in who has } \\
\text { land over the next ten years?" }\end{array}$ & $\begin{array}{l}\text { Sugarcane expansion land access: "I want you to } \\
\text { imagine that the price of sugarcane increased, and } \\
\text { people wanted to grow more sugarcane over the next } \\
\text { ten years. When you imagine this, do you think there } \\
\text { would be a change in who has land over the next ten } \\
\text { years?" }\end{array}$ \\
\hline
\end{tabular}

Respondents were asked about the expected consequences of each scenario on incomes and food availability through a combination of open- and closed-ended questions. These data were presented using descriptive statistics, and Pearson's chi-square tests (with p-values computed using Monte Carlo simulation) were used to explore differences between scenarios.

\section{Component 2: Structural equation modelling of relationships between respondent characteristics and mental health}

In addition to being asked expectations under the four scenarios, respondents also questioned about their household and personal characteristics and experiences of depressive symptoms. These data were analysed within a Bayesian structural equation model, as described below.

\section{Study variables}

The outcome variable was depressive symptom severity. The previous qualitative study indicated a range of symptoms overlapping with those used to diagnose several common mental disorders, including 
depression. A modified version of the nine-item Patient Health Questionnaire (PHQ-9) ${ }^{43}$ was used to measure depressive symptom severity. The PHQ-9 is widely used and is a recommended depression screening tool in the Diagnostic and Statistical Manual of Mental Disorders, Fifth Edition ${ }^{44}$. It has been used in multiple studies in Uganda (e.g., ${ }^{45,46}$ ). One item - related to suicidality - appeared to be misinterpreted during piloting and was removed. This modified instrument, referred to as the PHQ-8, is increasingly used and has equivalent diagnostic accuracy with the PHQ-947. The PHQ-8 asks respondents how many times they have experienced a given symptom in the past two weeks according to four response levels (with scoring from "Not at all" = 0 to "Nearly every day" $=3$ ). Depression severity can be calculated by summing a respondent's scores across items, with scores of 15 to 19 indicating moderately severe depressive symptoms and 20 to 24 indicating severe symptoms ${ }^{48}$. However, total PHQ-8 scores were not used within the statistical analysis. Instead, the PHQ-8 was used to estimate latent depressive symptom severity (see SM 2: Depression instrument). Plausible values were extracted from a graded response model, implemented with ten imputed datasets (introduced below). Furthermore, "thinking too much" is a colloquial term associated with psychological distress in the study area and many parts of East Africa ${ }^{49}$. A one-item instrument asked if respondents experienced "thinking too much", with the same response levels as used in the PHQ-8. This instrument was used to triangulate the current research results with those of a previous qualitative study (discussed below) ${ }^{9}$. 
Table 2

The a priori hypothesised associations between exposure and outcome variables in the structural equation model (where the exposure variable is expected to affect the outcome variable, apart from the when they are expected to have a bi-directional association indicated by co-variance) and a description of the exposure variables. See SM 3: Prior probability details for evidence supporting each prior. Key: ' + ' = positive association; '-' = negative association; '?' = uncertain direction of the association; RL = reference level, $N=$ normal distribution (where the first argument is the mean and the second is the variance), $B=$ beta distribution (with the arguments indicating the first and second shape parameters). All continuous variables are scaled and centred.

\begin{tabular}{|c|c|c|c|c|}
\hline $\begin{array}{l}\text { Outcome } \\
\text { variable }\end{array}$ & $\begin{array}{l}\text { Expected } \\
\text { association }\end{array}$ & $\begin{array}{l}\text { Exposure } \\
\text { variable }\end{array}$ & Description of parent variable & Prior distribution \\
\hline Depression & $(+)$ & $\begin{array}{l}\text { Food } \\
\text { insecurity }\end{array}$ & $\begin{array}{l}\text { A latent variable derived from } \\
\text { the Food Insecurity Experience } \\
\text { Scale (FIES) } \\
50\end{array}$ & $N(0.25,4)$ \\
\hline Depression & $(+)$ & $\begin{array}{l}\text { Economic } \\
\text { poverty }\end{array}$ & $\begin{array}{l}\text { An asset index adapted from } \\
\text { Travers, et al. }{ }^{51} \text {. }\end{array}$ & $N(0.25,4)$ \\
\hline $\begin{array}{l}\text { Food } \\
\text { insecurity }\end{array}$ & $\begin{array}{l}(+) \text { co- } \\
\text { variance }\end{array}$ & Forest use & $\begin{array}{l}\text { A latent variable from an } \\
\text { instrument designed to indicate } \\
\text { forest use. }\end{array}$ & $B(12,11)$ \\
\hline $\begin{array}{l}\text { Food } \\
\text { insecurity }\end{array}$ & $(-)$ & Farm size & $\begin{array}{l}\text { A latent variable from an } \\
\text { instrument designed to indicate } \\
\text { relative farm size. }\end{array}$ & $N(-0.25,4)$ \\
\hline $\begin{array}{l}\text { Food } \\
\text { insecurity }\end{array}$ & $(+)$ & $\begin{array}{l}\text { Economic } \\
\text { poverty }\end{array}$ & As above. & $N(0.25,4)$ \\
\hline $\begin{array}{l}\text { Food } \\
\text { insecurity }\end{array}$ & $(-)$ & $\begin{array}{l}\text { Distance to a } \\
\text { forest } \\
\text { reserve }\end{array}$ & $\begin{array}{l}\text { Distance from the household to } \\
\text { the edge of the nearest forest } \\
\text { reserve. }\end{array}$ & $N(-0.25,4)$ \\
\hline $\begin{array}{l}\text { Economic } \\
\text { poverty }\end{array}$ & $\begin{array}{l}(+) \text { co- } \\
\text { variance }\end{array}$ & Forest use & As above. & $B(12,11)$ \\
\hline $\begin{array}{l}\text { Economic } \\
\text { poverty }\end{array}$ & $\begin{array}{l}(-) \text { co- } \\
\text { variance }\end{array}$ & Farm size & As above. & $B(11,12)$ \\
\hline Depression & $(+)$ & Age & The respondent's age in years. & $N(0.25,4)$ \\
\hline Depression & $(+)$ & Gender & $\begin{array}{l}\mathrm{RL}=\text { male. The respondent's } \\
\text { gender. }\end{array}$ & $N(0.25,4)$ \\
\hline Depression & $(-)$ & Education & $\begin{array}{l}\mathrm{RL}=\text { no education. The } \\
\text { respondent's highest level of } \\
\text { education. }\end{array}$ & $N(-0.25,4)$ \\
\hline
\end{tabular}




\begin{tabular}{|c|c|c|c|c|}
\hline $\begin{array}{l}\text { Outcome } \\
\text { variable }\end{array}$ & $\begin{array}{l}\text { Expected } \\
\text { association }\end{array}$ & $\begin{array}{l}\text { Exposure } \\
\text { variable }\end{array}$ & Description of parent variable & Prior distribution \\
\hline Depression & $(-)$ & $\begin{array}{l}\text { Social } \\
\text { support }\end{array}$ & $\begin{array}{l}\text { A latent variable derived from a } \\
\text { modified version of the } \\
\text { Multidimensional Scale of } \\
\text { Perceived Social Support } \\
\text { (MSPSS) } \\
\text { (M. }\end{array}$ & $N(-0.25,4)$ \\
\hline Depression & $(+/ ?)$ & $\begin{array}{l}\text { Marital } \\
\text { status }\end{array}$ & $\begin{array}{l}\mathrm{RL}=\text { married once or } \\
\text { polygamous. Respondent's } \\
\text { marital status. }\end{array}$ & $\begin{array}{l}\text { Divorced/widow/er: } \\
N(0.25,4) \\
\text { Never married: } \\
N(0,9)\end{array}$ \\
\hline Depression & $\begin{array}{l}(-) \text { co- } \\
\text { variance }\end{array}$ & $\begin{array}{l}\text { Physical } \\
\text { health }\end{array}$ & $\begin{array}{l}\text { A single-item self-reported } \\
\text { health question from the } \\
\text { General Household Survey } \\
53,54 \text {. }\end{array}$ & $B(11,12)$ \\
\hline Depression & $(+)$ & $\begin{array}{l}\text { Alcohol } \\
\text { consumption }\end{array}$ & $\begin{array}{l}\text { How many days a week a } \\
\text { respondent drinks. }\end{array}$ & $N(0.25,4)$ \\
\hline Depression & $(+)$ & Smoking & $\begin{array}{l}\text { If the respondent smokes every } \\
\text { day. }\end{array}$ & $N(0.25,4)$ \\
\hline Depression & $(?)$ & $\begin{array}{l}\text { Community } \\
\text { name }\end{array}$ & $\begin{array}{l}\mathrm{RL}=\text { Nyabyeya Trading Centre. } \\
\text { The name of the community in } \\
\text { which the respondent resides. }\end{array}$ & $N(0,9)$ \\
\hline
\end{tabular}

The two focal social determinants of depression were food insecurity and economic poverty. Food security encompasses food sufficiency, nutrient adequacy, cultural acceptability, safety, certainty, and stability ${ }^{55}$. Our study focused on food sufficiency, experienced as a continuum from worrying about not having enough to eat to reducing food consumption ${ }^{56}$. We used the Food Insecurity Experience Scale (FIES) developed by the FAO Voices of the Hungry project. The FIES is simple and rapid to use, appears to be valid across cultural and socioeconomic contexts, and has been used in studies in Uganda ${ }^{55,57}$. We adjusted the FIES, asking respondents to consider their experiences over a three-month timeframe, considered most relevant in the study. The FIES was used to estimate latent food insecurity in ten sets of plausible values, using a two-parameter logistic item response model (see SM 4: FIES instrument).

Here, economic poverty means inadequate incomes and wealth, considered core aspects of material poverty ${ }^{58}$. Asset ownership is often used to indicate material poverty ${ }^{59}$. We used an asset index based on a survey developed by other researchers during a study conducted in a nearby area in 2015, which we piloted and adapted in March 201951. After data collection, ten of the 31 assets were excluded because they were either a) very uncommon, b) dependent on community-level access to utilities, or c) appeared to 
depend on a respondent's livelihood strategy (see SM 5: Asset index). Logistic principal component analysis was conducted with the remaining items. The first component scores were extracted, scaled and centred, and treated as a proxy for economic poverty.

The focal proxies for nature use were farm size and forest use. These were used as proxies because we could not directly measure interactions between residents and nature. Residents of the study site use a wide range of legally and illegally harvested forest resources ${ }^{60}$. Legally harvested resources include firewood, medicines, and some wild foods such as mushrooms. Illegal forest resources include game, timber, and wood for charcoal production. Given the sensitivity around direct questioning of illegal behaviours, we designed an instrument with seven Likert-scaled items (with five response levels ranging from "disagree a lot" to "agree a lot") to estimate forest use, also treated as a latent variable. These items included non-specific (focusing on the role of the forest in general) and specific (relating to household reliance on forest-related food and income) questions. For instance, one of the seven statements was, "Your household gets good money from things in the forest." This instrument was used to estimate latent forest use, again following steps described for estimating latent depression, with the extraction of ten sets of plausible values (see SM 6: Forest instrument).

Land boundaries and ownership are sensitive topics, and farms can be far from households where the surveys were conducted, so farm sizes were not physically measured. Instead, we designed an instrument with six Likert-scaled items (with five response levels ranging from "disagree a lot" to "agree a lot") to estimate relative farm size. For example, one of the statements read, "Your household's farm is smaller than most others in this community." This instrument was used to estimate latent relative farm size, following steps described above for estimating latent depression, before extracting ten sets of plausible values (see SM 7: Land instrument).

The analysis also included several covariates identified during the prior qualitative study at the same site and by reviewing relevant literature (Table 2, see SM 8: Social support instrument). Psychobiological vulnerability can moderate the links between social determinants and mental illness but was assumed to vary randomly in the population in relation to the exposure variable and was not measured.

\section{Statistical analysis}

Within the sample, $0.2 \%$ of the data were missing. These data were assumed to be missing at random (see SM 9: Patterns of missing data) and so were substituted through multivariate imputation by chained equations, where ten datasets were created containing imputed values (see SM 10: MICE).

A Bayesian structural equation model was fit for each of the imputed datasets. A Bayesian approach allowed us to include prior information in the analysis. A structural equation modelling approach allowed us to model associations between explanatory variables. The analysis was performed in the Stan computational framework (accessed using the 'blavaan' package ${ }^{61}$ ). The model's structure is based on the results of previous qualitative research in the study area (corresponding to Figure 2). Moderately informative priors were chosen when there was evidence of an expected direction of effect. For instance, 
substantial evidence suggests positive associations between food insecurity and depression risk ${ }^{10,62,63}$. Therefore, for this association, we chose a normal prior distribution that assumed a one standard deviation (s.d.) change in food security was associated with a 0.25 s.d. change in depressive symptom severity, with a variance of 4 (s.d. $=2)$.

Weakly informative priors were used where there was little prior evidence of an expected direction of effect. Using a seed value of 4343 , the model was run for 4,000 burn-in and 4,000 post-burn-in iterations $(8,000$ total), with the posterior distribution estimated with the Markov Chain Monte Carlo sampler, across four Markov chains, following McElreath ${ }^{64}$. The models were evaluated according to the ten steps described in the WAMBS-Checklist (see SM 11: Model diagnostics) ${ }^{65}$. Finally, the model results associated with each of the ten imputed datasets were pooled by combining the posterior distributions. Point estimates are the median of the posterior distribution.

We also implemented several post hoc supplementary analyses. First, we modelled the association between "thinking too much" and latent depressive symptom severity using a Bayesian ordinal regression, with weakly informative priors (see SM 12: Supplementary analysis 1). Second, we repeated the primary analysis described above, replacing depressive symptom severity with "thinking too much" (treated as a continuous variable, see SM 13: Supplementary analysis 2).

\section{Results}

The survey was completed by 695 respondents from 11 communities (Table 3 ). Of these, $11.2 \%$ reported moderately severe depressive symptoms (PHQ-8 scores $=[15,19])$ and $4.6 \%$ reported severe symptoms $(\mathrm{PHQ}-8$ scores $=[20,24])$. We also found a positive association between the reported experience of "thinking too much" and PHQ-8 scores (log odds $=1.27,95 \% \mathrm{Cl}=1.22-1.31)$. For instance, someone with a PHQ-8 score of 20 was 2.38 times more likely to report "thinking too much" nearly every day than someone with a score of 10 (see SM 12: Supplementary analysis 1). 
Table 3

Overall and gender-differentiated respondent characteristics. Numeric variables are described by their mean (and standard deviations).

Categorical data are described by their counts (and percentages). Key: PHQ-8 = eight-item Patient Health Questionnaire, FIES = Food

Insecurity Experience Scale, Alcohol consumption = how many days a week a respondent consumes alcohol.

\begin{tabular}{|c|c|c|c|}
\hline \multirow[t]{2}{*}{ Characteristic } & Overall & Female & Male \\
\hline & $N=695$ & $N=414$ & $N=281$ \\
\hline PHQ-8 score & $9.7(4.9)$ & $10.1(5.0)$ & $9.1(4.8)$ \\
\hline \multicolumn{4}{|l|}{ Strong thoughts? } \\
\hline Not at all & $96(14 \%)$ & $63(15 \%)$ & $33(12 \%)$ \\
\hline Few days & $241(35 \%)$ & $132(32 \%)$ & $109(39 \%)$ \\
\hline More than half the days & $97(14 \%)$ & $54(13 \%)$ & $43(15 \%)$ \\
\hline Nearly every day & $261(38 \%)$ & $165(40 \%)$ & $96(34 \%)$ \\
\hline FIES score & $4.9(2.5)$ & $5.2(2.5)$ & $4.6(2.5)$ \\
\hline Age & $35.6(11.4)$ & $34.8(11.1)$ & $36.8(11.8)$ \\
\hline \multicolumn{4}{|l|}{ Education } \\
\hline No education & $63(9.1 \%)$ & $58(14 \%)$ & $5(1.8 \%)$ \\
\hline Primary & $465(67 \%)$ & $282(68 \%)$ & $183(65 \%)$ \\
\hline Secondary & $144(21 \%)$ & $67(16 \%)$ & 77 (27\%) \\
\hline Beyond Secondary & $23(3.3 \%)$ & $7(1.7 \%)$ & $16(5.7 \%)$ \\
\hline \multicolumn{4}{|l|}{ Marital status } \\
\hline Divorced or widow/er & $117(17 \%)$ & $95(23 \%)$ & $22(7.8 \%)$ \\
\hline Married/polygamous & $532(77 \%)$ & $298(72 \%)$ & $234(83 \%)$ \\
\hline Never married & $46(6.6 \%)$ & $21(5.1 \%)$ & $25(8.9 \%)$ \\
\hline \multicolumn{4}{|l|}{ Health } \\
\hline Very bad & $31(4.5 \%)$ & $19(4.6 \%)$ & $12(4.3 \%)$ \\
\hline Bad & $75(11 \%)$ & $51(12 \%)$ & $24(8.5 \%)$ \\
\hline Fair & $364(52 \%)$ & $208(50 \%)$ & $156(56 \%)$ \\
\hline Good & $159(23 \%)$ & 97 (23\%) & $62(22 \%)$ \\
\hline Very good & 66 (9.5\%) & 39 (9.4\%) & 27 (9.6\%) \\
\hline
\end{tabular}




\begin{tabular}{|llll|}
\hline Characteristic & $\begin{array}{l}\text { Overall } \\
\mathbf{N}=\mathbf{6 9 5}\end{array}$ & $\begin{array}{l}\text { Female } \\
\mathbf{N}=\mathbf{4 1 4}\end{array}$ & $\begin{array}{l}\text { Male } \\
\mathbf{N}=\mathbf{2 8 1}\end{array}$ \\
\hline Alcohol consumption & $0.5(1.2)$ & $0.3(1.0)$ & $0.7(1.4)$ \\
\hline Daily smoker & & & \\
\hline No & $619(89 \%)$ & $395(95 \%)$ & $224(80 \%)$ \\
\hline Yes & $76(11 \%)$ & $19(4.6 \%)$ & $57(20 \%)$ \\
\hline Language & & & \\
\hline English & $96(14 \%)$ & $37(8.9 \%)$ & $59(21 \%)$ \\
\hline Kiswahili & $502(72 \%)$ & $312(75 \%)$ & $190(68 \%)$ \\
\hline Runyoro & $97(14 \%)$ & $65(16 \%)$ & $32(11 \%)$ \\
\hline
\end{tabular}

\section{Component 1: Effects of land management scenarios on access}

In total, 353 respondents were asked about either the 'BAU forest access' (188) or 'restricted forest access' (165) scenarios. Most of these respondents felt households would get less food (Figure 4a.) and fewer income-generating 'things' (Figure 4d.) from the forest over the next ten years. Expected declines in food and 'things' were significantly higher among 'restricted forest access' scenario respondents. Many of those expecting declines indicated that this would be because residents would be stopped from accessing the forest (Figure 4b. and 4e.), particularly in the 'restricted forest access' scenario. The majority believed that households who got less food and fewer 'things' from the forest would experience greater food insecurity (Figure 4c.) and poverty (Figure 4f.), with no significant difference between scenarios.

The other half of respondents (342) respondents were asked to consider the 'BAU land access' (163) and 'sugarcane expansion land access' (179) scenarios. Most of these respondents expected a change in who has land over the next ten years, with no significant difference in responses between the two scenarios (Figure 5a.). Among those expecting a change, almost all said wealthier households would gain land, and poorer households would lose it, with no significant difference between scenarios (Figure 5b. and 5c.). While many indicated that households would buy or rent this land, a sizable proportion also believed this land would be "taken" from others (Figure 5d.). Many expecting a change in land distributions indicated that acquired land would be used for cash crops, particularly in the 'sugarcane expansion land access' scenario (Figure 5e.). In both scenarios, many indicated that a decline in a households land would lead to an increase in poverty (Figure $5 \mathrm{f}$.) and hunger (Figure $5 \mathrm{~g}$.), although poverty increases were slightly lower in the 'sugarcane expansion land access' scenario. 


\section{Component 2: The relationship between forest use, farm size and social determinants of depression}

Within the statistical analysis, forest use was positively associated with food insecurity and (with less statistical certainty) economic poverty (Figure 6a). Conversely, farm size was negatively associated with economic poverty and food insecurity. Furthermore, food insecurity and economic poverty were positively associated with depressive symptom severity.

Many of the hypothesised associations between depressive symptom severity and the covariates were also supported by the analysis. For instance, men and those with higher education, greater social support, and better health reported lower depressive symptom severity. Additionally, the analysis was repeated with the software's default weakly informative priors, the results of which were effectively the same as those presented here (see SM 11: Model diagnostics).

When looking at the total effects, those with one s.d. higher forest use than the mean had an estimated $0.03(95 \% \mathrm{Cl}=0.00-0.05$, Figure $6 \mathrm{~b})$ s.d. higher depressive symptom severity. Similarly, those with one s.d. larger farm sizes than the mean reported $0.08(95 \% \mathrm{Cl}=0.11$ to 0.05$)$ s.d. lower depression severity. In other words, forest users were at a slightly greater risk of depression, but those with larger farms were at a slightly lower risk.

We repeated the analysis, substituting latent depressive symptom severity with an instrument asking about "thinking too much". The results of this supplementary analysis were largely consistent with those presented above, although with some differences associated with the covariates (see SM 13: Supplementary analysis 2).

\section{Discussion}

Landscape management can often change patterns of access to nature, with complex outcomes for human wellbeing ${ }^{4,5}$. Yet, we are unaware of any studies predicting how changing access to land and forest resources influence social determinants of mental illness. Our study helps address this gap, describing the expected consequences of changes in landscape management on social determinants of depression in a Global South case study. In the following, we summarise our results in relation to our original research questions and hypothesises, discuss key study considerations, and then situate the results within a wider research and policy context.

Our respondents expected that restricted forest access - in both forest scenarios - would increase food insecurity and economic poverty among forest-using households (RQ1). Moreover, our modelling suggested that forest use was positively associated with food insecurity and, to a lesser extent, economic poverty (H1). Food insecurity and poverty appeared to be strong social determinants of depressive symptom severity $(\mathrm{H} 3)$. Combined, these results suggest that conservation approaches that restrict forest access may exacerbate social determinants of depression among forest users. 
Furthermore, respondents also expected more inequitable land distribution, largely attributed to contract sugarcane farming, with those losing land being at greater risk of food insecurity and economic poverty (RQ2). Our statistical analysis suggested that farm size was negatively associated with poverty and food insecurity $(\mathrm{H} 2)$. Together, these results suggest that agricultural approaches that restrict access to land may worsen social determinants of depression among small-scale farmers.

However, we found relatively little difference within each scenario pair. This result could be because the hypothetical interventions resembled land management practices that were expected to occur regardless. For instance, residents who have witnessed the expansion of contract farming over the last two decades may expect this trend to continue. If this is the case, those who influence lands management, such as the Ugandan government, should consider policies that actively divert from this trajectory, discussed below.

\section{Study considerations}

Our approach combining modelling of current epidemiological dynamics with expectations under different scenarios allows us to explore plausible land management outcomes in the future. We believed that residents were well-positioned to evaluate the impacts of changing land management on their own lives. Yet, scenario-based interviews have several limitations. First, a respondents ability to accurately predict their actions may decline as the scenarios become more complex ${ }^{38}$. However, we presented relatively simple scenarios, which were extensions of current land management practices. Second, these evaluations may not have fully accounted for indirect, unintuitive, or hidden feedbacks that might influence residents in complex socio-ecological systems. For instance, enforcing hunting bans might lead to increased populations of crop-raiding wildlife, further harming food security. Finally, respondents may provide strategic responses if they believe this will influence the choice of intervention. We sought to reduce this potential effect by explaining that no planned intervention was associated with the research. In general, a large body of research explores the limitations of expert elicitation methods in conservation and related fields (e.g., ${ }^{66}$ ). Many of these limitations might also apply when using scenario-based interviews, suggesting the potential value of structured elicitation protocols when using these interviews (e.g., $\left.{ }^{67}\right)$. Equally, a researcher's positionality may influence which and how scenarios are presented, how participants respond, and how the results are interpreted. Therefore, we suggest the need for reflexivity when using these methods, as in other areas of landscape research ${ }^{68,69}$. Finally, while there is increasing application of scenario-based interviews in conservation and related fields (e.g., ${ }^{38}$ ), there appears to be limited evidence testing how well respondents predictions perform against actual interventions.

We also assumed that psychobiological vulnerability varied randomly with respect to the exposure variables, such as economic poverty. However, there can be dynamic bi-directional feedbacks between mental illness and life stressors over an individual's life course. For instance, previous research in the study site suggested that "thinking too much" was linked with impaired livelihood activities, potentially worsening social determinants of psychological distress ${ }^{9}$. These dynamic feedbacks represent an 
exciting opportunity for future time-series research, exploring how landscapes, livelihoods, and mental health co-evolve over time.

We restricted our study population to farming households and did not consider the impacts of land management on the mental health of other groups. However, contract farming can have complex effects on non-farmers, such as labourers ${ }^{36,37}$. The expansion of sugarcane farming in the study area has provided jobs for landless residents and migrants ${ }^{60}$, so might have supported the mental health of these groups. These potential benefits should be understood and accounted for when weighing up the suitability of different land management approaches.

The PHQ-8 has been used internationally and is based on an instrument that has been used in Uganda ${ }^{45,46}$. However, western diagnostic criteria and psychological concepts might not be universally appropriate and overlook culturally relative syndromes ${ }^{49}$. Prior research in the study site suggested partial overlap in symptoms associated with "thinking too much" and depression ${ }^{9}$. Our study found a strong association between depressive symptom severity, estimated using the PHQ-8, and reported experiences of "thinking too much". Moreover, "thinking too much" had similar associations with our explanatory variables as found in the primary analysis. This result suggests that our findings - and their broader policy implications - are unlikely to be an artefact of using a western diagnostic tool.

\section{Land management policy and mental health}

Common mental disorders are a leading cause of morbidity and disability ${ }^{12}$, but there has been a "collective failure to respond to this global health crisis" ${ }^{7}$. Recognising this, the field of global mental health has emerged, which seeks to enhance both the treatment and prevention of mental illness worldwide ${ }^{70}$. As part of this prevention, there have been recent calls to better understand and manage the social, cultural, and economic causes of mental illness. For instance, Collins, et al. ${ }^{8}$ highlight the need to better "support community environments that promote physical and mental well-being throughout life". However, our results suggest the need to look beyond the social context to understand distal socioecological factors indirectly influencing mental health. These factors include how the management of landscape can influence social determinants of mental illness. Moreover, our study responds to calls for forward-looking predictive landscape planning ${ }^{71}$. In doing so, our study suggests potential trade-offs that should be accounted for within land management for holistic sustainable development.

Protected areas will remain a core part of global conservation efforts, with the " 30 by 30 " plan to double their current extent over the next decade ${ }^{1}$. The social impacts of this expansion may vary depending on residents' context-dependent relationships with nature and access rules. However, our results suggest restrictive protected areas may threaten the mental health of those whose livelihoods depend on access to nature. In these contexts, gazetting strictly protected areas might undermine progress to health (SDG 3) and other sustainable development goals among some groups. However, protected areas are unlikely to be unambiguously bad for mental health. For example, Buckley, et al. ${ }^{72}$ estimated that the economic value of improved mental health among visitors to protected areas was several orders of magnitude 
greater than their management budgets. Nevertheless, many citizens in biodiverse countries depend on nature for their basic needs while being under-served by mental healthcare services ${ }^{73,74}$. So, promoting the expansion of protected areas in these places might exacerbate social determinates of mental illness among already vulnerable populations. Recognising this, governments might explore alternatives to strictly protected areas. While our study did not evaluate these alternatives, our results suggest the potential benefits of fostering sustainable forest use. In Uganda, this could include strengthening and promoting collaborative forest management agreements, a legal mechanism with dual aims of enhancing livelihoods while conserving forests ${ }^{75}$. More broadly, mounting evidence shows that Indigenous groups and local communities play vital roles in protecting nature ${ }^{76,77}$. So governments, conservation organizations, and other actors might consider ways to support residents to use nature sustainably. This support could include, for example, strengthening residents collective land tenure, selfdetermined governance systems, and their ability to defend against external drivers of nature loss ${ }^{32}$. Further research is needed to evaluate how land management approaches can effectively support residents' mental health. However, such alternatives might help prevent mental illness (SDG 3) while meeting other sustainable development goals.

Contract farming has been promoted as a tool for more inclusive agricultural development, including within Uganda ${ }^{34,78}$. However, our study corroborates other research suggesting contract farming can increase inequality and worsen outcomes in some cases ${ }^{36,37}$. Moreover, contract farming approaches may occur hand-in-hand with other factors - like global market exposure, indebtedness, and uncertain yields - linked to high rates of suicide in some farming communities ${ }^{79,80}$. In general, the extent to which contract farming contributes to equitable sustainable development depends on how well it engages small-scale farmers ${ }^{34}$. Around Budongo Forest, contract farming has largely failed to engage the poorest farming households and might have restricted their access to land, with similar outcomes observed in other parts of Uganda and Africa (e.g., ${ }^{36,37,81}$ ). Further research is needed to understand how policy responses to these challenges could support mental health. However, these responses could include making contract farming more inclusive, such as prioritising agricultural extension services to the poorest in communities. However, more inclusive contract farming may not always be feasible, suggesting the value of alternative options for the poorest in communities. In our study site, this might include promoting collaborative forest management with households with limited land. Moreover, land managers might consider ways to reduce adverse spillover effects, such as enhancing tenure by making it easier and cheaper for poorer households to claim land titles.

\section{Conclusion}

We show how the expansion of strictly protected areas may harm the mental health of forest users. We also illustrate how contract-farming approaches that worsen inequitable land distributions may harm the mental health of small-scale farmers. Therefore, decision-makers seeking to support mental health should be wary of approaches that impair livelihood activities by restricting access to nature. However, health is only one of the multiple sustainable development objectives, and the links between landscapes 
and wellbeing can be complex and context-dependent ${ }^{4,5}$. Given this complexity, navigating trade-offs and synergies offered by different land management approaches can be challenging. Future research is needed to explore how landscape management could support mental health alongside other societal priorities. However, several principles might help in this process. First, a "whole-of-government" approach

- encouraging dialogue and strategic planning across government agencies ${ }^{1}$ - can help promote coherent and coordinated sustainable development policy. For example, this could include exploring if sustainable forest use interventions could be a tool for preventing mental illness. Second, decisionmakers, practitioners, and researchers should be wary of one-size-fits-all solutions, such as plans focused on expanding protected areas. Instead, a "whole-of-society" approach - strengthening inclusion and participation of diverse societal actors ${ }^{1}$ - might help find locally appropriate and socially just landscape solutions. This approach could include scenario-based stakeholder engagement for inclusive, transparent, and forward-looking landscape planning. These and other approaches may help reduce the immense global burden of mental illness, supporting sustainable development and living in harmony with nature.

\section{Declarations}

\section{Acknowledgements}

We thank the participating residents of Nyabyeya and Kabango parishes and Moses Musiimenta, Susan Lajiki, Liberty Anichan, Gilbert Guzaarwa, and Joseph Rushenjule for their assistance with the study. This work was supported by the Natural Environment Research Council (grant number NE/L002612/1), Royal Society of Tropical Medicine and Hygiene (Small Grants Programme), the Parkes Foundation Small Grant Fund, and the Africa-Oxford Initiative Travel Grant. The funders had no involvement in study design, in the collection, analysis, and interpretation of data, in the writing of the report, and in the decision to submit the article for publication.

\section{Competing interests}

The authors declare no competing interests.

\section{Data and code availability}

The anonymised data used in the statistical analysis is available from Figshare (DOl: $10.6084 / \mathrm{m} 9$. figshare.16955221). The code used in the statistical analysis is available from: https://github.com/Pienkowski/Uganda_quant_analysis_pub. Please contact the authors directly for the scenario data.

\section{Author contributions}


TP: conceptualization; data curation; formal analysis; funding acquisition; investigation; methodology; project administration; resources; validation; visualization; roles/writing - original draft; writing - review \& editing. AK: conceptualization; funding acquisition; methodology; supervision; validation; visualization; writing - review \& editing. EK: conceptualization; methodology; writing - review \& editing. CA: conceptualization; methodology. EJMG: conceptualization; funding acquisition; methodology; resources; supervision; validation; visualization; writing - review \& editing.

\section{References}

1 Convention on Biological Diversity. First draft of the post-2020 global biodiversity framework. 1-12 (Convention on Biological Diversity, 2021).

2 United Nations General Assembly. Transforming our world: The 2030 Agenda for Sustainable Development. 1-35 (United Nations General Assembly, 2015).

3 Clark, M., Hill, J. \& Tilman, D. The diet, health, and environment trilemma. Annual Review of Environment and Resources 43, 109-134, doi:10.1146/annurev-environ-102017-025957 (2018).

4 Lu, N., Liu, L., Yu, D. \& Fu, B. Navigating trade-offs in the social-ecological systems. Current Opinion in Environmental Sustainability 48, 77-84, doi:https://doi.org/10.1016/j.cosust.2020.10.014 (2021).

5 Ellis, E. C., Pascual, U. \& Mertz, O. Ecosystem services and nature's contribution to people: negotiating diverse values and trade-offs in land systems. Current Opinion in Environmental Sustainability 38, 86-94, doi:https://doi.org/10.1016/j.cosust.2019.05.001 (2019).

6 World Health Organization (WHO). Promoting mental health: concepts, emerging evidence, practice: summary report. 1-70 (World Health Organization (WHO), Geneva, Switzerland, 2004).

7 Patel, V. et al. The Lancet Commission on global mental health and sustainable development. The Lancet 392, 1553-1598, doi:10.1016/S0140-6736(18)31612-X (2018).

8 Collins, P. Y. et al. Grand challenges in global mental health. Nature 475, 27-30, doi:10.1038/475027a (2011).

9 Pienkowski, T. et al. The role of nature conservation and commercial farming in psychological distress among rural Ugandans. bioRxiv, 2021.2006.2008.446718, doi:10.1101/2021.06.08.446718 (2021).

10 Lund, C. et al. Social determinants of mental disorders and the Sustainable Development Goals: a systematic review of reviews. The Lancet Psychiatry 5, 357-369, doi:10.1016/s2215-0366(18)30060-9 (2018).

11 Nilsson, M., Griggs, D. \& Visbeck, M. Policy: map the interactions between Sustainable Development Goals. Nature 534, 320-322, doi:https://doi.org/10.1038/534320a (2016). 
12 Prince, M. et al. No health without mental health. The Lancet 370, 859-877, doi:10.1016/s01406736(07)61238-0 (2007).

13 GBD 2017 Disease and Injury Incidence and Prevalence Collaborators (GBD). Global, regional, and national incidence, prevalence, and years lived with disability for 354 diseases and injuries for 195 countries and territories, 1990-2017: a systematic analysis for the Global Burden of Disease Study 2017. Lancet 392, 1789-1858, doi:10.1016/s0140-6736(18)32279-7 (2018).

14 Vigo, D. V., Kestel, D., Pendakur, K., Thornicroft, G. \& Atun, R. Disease burden and government spending on mental, neurological, and substance use disorders, and self-harm: cross-sectional, ecological study of health system response in the Americas. The Lancet Public Health 4, e89-e96, doi:10.1016/S2468-2667(18)30203-2 (2019).

15 Lund, C. et al. Poverty and common mental disorders in low and middle income countries: a systematic review. Social Science \& Medicine 71, 517-528, doi:10.1016/j.socscimed.2010.04.027 (2010).

16 Kinyanda, E. et al. Poverty, life events and the risk for depression in Uganda. Social Psychiatry and Psychiatric Epidemiology 46, 35-44, doi:10.1007/s00127-009-0164-8 (2011).

17 Kinyanda, E., Waswa, L., Baisley, K. \& Maher, D. Prevalence of severe mental distress and its correlates in a population-based study in rural south-west Uganda. BMC Psychiatry 11, 1-9, doi:10.1186/1471-244X-11-97 (2011).

18 Intergovernmental Science-Policy Platform on Biodiversity and Ecosystem Services (IPBES). Summary for policymakers of the global assessment report on biodiversity and ecosystem services of the Intergovernmental Science-Policy Platform on Biodiversity and Ecosystem Services. 1-56 (Bonn, Germany, 2020).

19 United Nations (UN). Convention on biological diversity. 1-30 (United Nations (UN), Rio de Janeiro, Brazil, 1992).

20 Díaz, S. et al. The IPBES Conceptual Framework - connecting nature and people. Current Opinion in Environmental Sustainability 14, 1-16, doi:10.1016/j.cosust.2014.11.002 (2015).

21 Ickowitz, A., Powell, B., Salim, M. A. \& Sunderland, T. C. H. Dietary quality and tree cover in Africa. Global Environmental Change 24, 287-294, doi:10.1016/j.gloenvcha.2013.12.001 (2014).

22 Ribot, J. C. \& Peluso, N. L. A theory of access. Rural Sociology 68, 153-181, doi:https://doi.org/10.1111/j.1549-0831.2003.tb00133.x (2003).

23 Hicks, C. C. \& Cinner, J. E. Social, institutional, and knowledge mechanisms mediate diverse ecosystem service benefits from coral reefs. Proceedings of the National Academy of Sciences 111, 17791, doi:10.1073/pnas.1413473111 (2014). 
24 Blaikie, P. Environment and access to resources in Africa. Africa 59, 18-40, doi:10.2307/1160761 (1989).

25 Berbés-Blázquez, M., González, J. A. \& Pascual, U. Towards an ecosystem services approach that addresses social power relations. Current Opinion in Environmental Sustainability 19, 134-143, doi:https://doi.org/10.1016/j.cosust.2016.02.003 (2016).

26 Thoms, C. A. Community control of resources and the challenge of improving local livelihoods: a critical examination of community forestry in Nepal. Geoforum 39, 1452-1465, doi:https://doi.org/10.1016/j.geoforum.2008.01.006 (2008).

27 Peluso, N. L. \& Lund, C. New frontiers of land control: introduction. The Journal of Peasant Studies 38, 667-681, doi:10.1080/03066150.2011.607692 (2011).

28 Ostrom, E. A diagnostic approach for going beyond panaceas. Proceedings of the National Academy of Sciences 104, 15181-15187, doi:10.1073/pnas.0702288104 (2007).

29 United Nations Environment World Conservation Monitoring Centre (UNEP-WCMC) \& International Union for Conservation of Nature (IUCN). Protected Planet: The World Database on Protected Areas (WDPA), <https://www.protectedplanet.net/> (2020).

30 Pullin, A. S. et al. Human well-being impacts of terrestrial protected areas. Environmental Evidence 2, 1-41, doi:10.1186/2047-2382-2-19 (2013).

31 Schleicher, J. et al. Protecting half of the planet could directly affect over one billion people. Nature Sustainability 2, 1094-1096, doi:10.1038/s41893-019-0423-y (2019).

32 ICCA Consortium. Territories of Life: 2021 report. 1-153 (ICCA Consortium, 2021).

33 Food and Agriculture Organization of the United Nations (FAO). FAOSTAT, $<$ https://www.fao.org/faostat/en/\#data> (2021).

34 Vabi Vamuloh, V., Panwar, R., Hagerman, S. M., Gaston, C. \& Kozak, R. A. Achieving Sustainable Development Goals in the global food sector: a systematic literature review to examine small farmers engagement in contract farming. Business Strategy and Development 2, 276-289, doi:https://doi.org/10.1002/bsd2.60 (2019).

35 Meemken, E.-M. \& Bellemare, M. F. Smallholder farmers and contract farming in developing countries. Proceedings of the National Academy of Sciences 117, 259, doi:10.1073/pnas.1909501116 (2020).

36 Bellemare, M. F. \& Bloem, J. R. Does contract farming improve welfare? A review. World Development 112, 259-271, doi:https://doi.org/10.1016/j.worlddev.2018.08.018 (2018). 
37 Hall, R., Scoones, I. \& Tsikata, D. Plantations, outgrowers and commercial farming in Africa: agricultural commercialisation and implications for agrarian change. The Journal of Peasant Studies 44, 515-537, doi:10.1080/03066150.2016.1263187 (2017).

38 Travers, H., Clements, T. \& Milner-Gulland, E. J. Predicting responses to conservation interventions through scenarios: a Cambodian case study. Biological Conservation 204, 403-410, doi:https://doi.org/10.1016/j.biocon.2016.10.040 (2016).

39 Cinner, J. E., Folke, C., Daw, T. \& Hicks, C. C. Responding to change: using scenarios to understand how socioeconomic factors may influence amplifying or dampening exploitation feedbacks among Tanzanian fishers. Global Environmental Change 21, 7-12, doi:https://doi.org/10.1016/j.gloenvcha.2010.09.001 (2011).

40 Kyongera, D. Mapping private sector investments and their impacts on great ape habitats in Uganda's Albertine Rift region. 1-50 (International Institute for Environment and Development (IIED), 2015).

41 Hansen, M. C. et al. High-resolution global maps of 21 st-century forest cover change. Science 342, 850-853, doi:10.1126/science.1244693 (2013).

42 National Planning Authority of Uganda. Third national development plan (NDP III) 2020/21 2024/25. 1-341 (Gobernment of Uganda, 2020).

43 Kroenke, K., Spitzer, R. L. \& Williams, J. B. W. The PHQ-9: validity of a brief depression severity measure. Journal of General Internal Medicine 16, 606-613, doi:10.1046/j.1525-1497.2001.016009606.x (2001).

44 American Psychiatric Association. Diagnostic and Statistical Manual of Mental Disorders (DSM-5). 5th edn, 1-947 (American Psychiatric Association, 2013).

45 Wagner, G. J. et al. The role of depression in work-related outcomes of HIV treatment in Uganda. International Journal of Behavioral Medicine 21, 946-955, doi:10.1007/s12529-013-9379-x (2014).

46 Kinyanda, E. et al. Effectiveness and cost-effectiveness of integrating the management of depression into routine HIV Care in Uganda (the HIV + D trial): a protocol for a cluster-randomised trial. International Journal of Mental Health Systems 15, 45, doi:10.1186/s13033-021-00469-9 (2021).

47 Wu, Y. et al. Equivalency of the diagnostic accuracy of the PHQ-8 and PHQ-9: a systematic review and individual participant data meta-analysis. Psychological Medicine 50, 1368-1380, doi:https://doi.org/10.1017/S0033291719001314 (2020).

48 Kroenke, K. et al. The PHQ-8 as a measure of current depression in the general population. Journal of Affective Disorders 114, 163-173, doi:https://doi.org/10.1016/j.jad.2008.06.026 (2009). 
49 Kaiser, B. N. et al. Thinking too much: a systematic review of a common idiom of distress. Social Science and Medicine 147, 170-183, doi:10.1016/j.socscimed.2015.10.044 (2015).

50 Jones, A. D., Ngure, F. M., Pelto, G. \& Young, S. L. What are we assessing when we measure food security? A compendium and review of current metrics. Advances in Nutrition 4, 481-505, doi:10.3945/an.113.004119 (2013).

51 Travers, H. et al. Understanding complex drivers of wildlife crime to design effective conservation interventions. Conservation Biology 0, 1-10, doi:10.1111/cobi.13330 (2019).

52 Zimet, G. D., Powell, S. S., Farley, G. K., Werkman, S. \& Berkoff, K. A. Psychometric characteristics of the Multidimensional Scale of Perceived Social Support. Journal of Personality Assessment 55, 610617, doi:10.1080/00223891.1990.9674095 (1990).

53 Bowling, A. Just one question: if one question works, why ask several? Journal of Epidemiology and Community Health 59, 342-345, doi:10.1136/jech.2004.021204 (2005).

54 Office for National Statistics (ONS). General household survey 2007 household - household and individual questionnaires. 1-140 (Office for National Statistics, Newport, UK, 2007).

55 Coates, J. Build it back better: deconstructing food security for improved measurement and action. Global Food Security 2, 188-194, doi:10.1016/j.gfs.2013.05.002 (2013).

56 Ballard, T., Kepple, A. \& Cafiero, C. The Food Insecurity Experience Scale: development of a global standard for monitoring hunger worldwide. 1-58 (Food and Agriculture Organization, Rome, Italy, 2013).

57 Sseguya, H., Mazur, R. E. \& Flora, C. B. Social capital dimensions in household food security interventions: implications for rural Uganda. Agriculture and Human Values 35, 117-129, doi:10.1007/s10460-017-9805-9 (2017).

58 Narayan, D., Chambers, R., Shah, M. K. \& Petesch, P. Voices of the Poor: Crying Out for Change. 1332 (Oxford University Press, 2000).

59 Harttgen, K. \& Vollmer, S. Using an asset index to simulate household income. Economics Letters 121, 257-262, doi:https://doi.org/10.1016/j.econlet.2013.08.014 (2013).

60 Babweteera, F. et al. in Conservation and Development in Uganda (eds C. Sandbrook, C. J. Cavanagh, \& D. M. Tumusiime) 104-122 (Routledge, 2018).

61 Merkle, E. C., Fitzsimmons, E., Uanhoro, J. \& Goodrich, B. Efficient Bayesian structural equation modeling in Stan. arXiv preprint, doi: arXiv:2008.07733v1 (2020).

62 Kinyanda, E. et al. Major depressive disorder and suicidality in early HIV infection and its association with risk factors and negative outcomes as seen in semi-urban and rural Uganda. Journal of 
Affective Disorders 212, 117-127, doi:10.1016/j.jad.2017.01.033 (2017).

63 Weaver, L. J. \& Hadley, C. Moving beyond hunger and nutrition: a systematic review of the evidence linking food insecurity and mental health in developing countries. Ecology of Food and Nutrition 48, 263-284, doi:10.1080/03670240903001167 (2009).

64 McElreath, R. Statistical Rethinking: A Bayesian Course with Examples in R and Stan. 1st edn, 1505 (Chapman \& Hall/CRC, 2016).

65 Depaoli, S. \& Van de Schoot, R. Improving transparency and replication in Bayesian statistics: The WAMBS-Checklist. Psychological Methods 22, 240, doi:10.1037/met0000065 (2017).

66 Burgman, M. A. et al. Expert status and performance. PLOS ONE 6, e22998, doi:10.1371/journal.pone.0022998 (2011).

67 Hemming, V., Burgman, M. A., Hanea, A. M., McBride, M. F. \& Wintle, B. C. A practical guide to structured expert elicitation using the IDEA protocol. Methods in Ecology and Evolution 9, 169-180, doi:https://doi.org/10.1111/2041-210X.12857 (2018).

68 Bennett, N. J. et al. Conservation social science: understanding and integrating human dimensions to improve conservation. Biological Conservation 205, 93-108, doi:https://doi.org/10.1016/j.biocon.2016.10.006 (2017).

69 Montana, J., Elliott, L., Ryan, M. \& Wyborn, C. The need for improved reflexivity in conservation science. Environmental Conservation, 1-3, doi:10.1017/s0376892920000326 (2020).

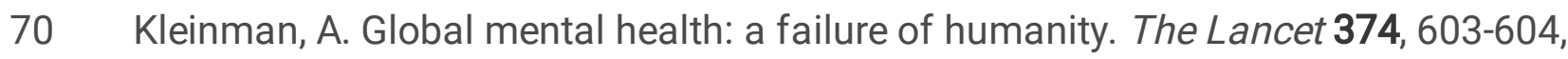
doi:https://doi.org/10.1016/S0140-6736(09)61510-5 (2009).

71 Travers, H. et al. A manifesto for predictive conservation. Biological Conservation 237, 12-18, doi:10.1016/j.biocon.2019.05.059 (2019).

72 Buckley, R. et al. Economic value of protected areas via visitor mental health. Nature Communications 10, 5005, doi:10.1038/s41467-019-12631-6 (2019).

73 Saxena, S., Thornicroft, G., Knapp, M. \& Whiteford, H. Resources for mental health: scarcity, inequity, and inefficiency. The Lancet 370, 878-889, doi:https://doi.org/10.1016/S0140-6736(07)61239-2 (2007).

74 Fedele, G., Donatti, C. I., Bornacelly, I. \& Hole, D. G. Nature-dependent people: mapping human direct use of nature for basic needs across the tropics. Global Environmental Change, 102368, doi:https://doi.org/10.1016/j.gloenvcha.2021.102368 (2021). 
75 Turyahabwe, N., Agea, J. G., Tweheyo, M. \& Tumwebaze, S. B. in Sustainable Forest Management: Case Studies (ed J.J. Diez) Ch. 3, 51-74 (InTech, 2012).

76 Garnett, S. T. et al. A spatial overview of the global importance of Indigenous lands for conservation. Nature Sustainability 1, 369-374, doi:10.1038/s41893-018-0100-6 (2018).

77 Dawson, N. M. et al. The role of Indigenous peoples and local communities in effective and equitable conservation. Ecology and Society 26, doi:10.5751/ES-12625-260319 (2021).

78 Ministry of Agriculture, A. I. a. F. Agriculture sector strategic plan 2015/16 - 2019/20 "Draft". 1-199 (Government of Uganda, 2016).

79 Mohanakumar, S. \& Sharma, R. K. Analysis of farmer suicides in Kerala. Economic and Political Weekly 41, 1553-1558 (2006).

80 Bryant, L. \& Garnham, B. Beyond discourses of drought: the micro-politics of the wine industry and farmer distress. Journal of Rural Studies 32, 1-9, doi:https://doi.org/10.1016/j.jrurstud.2013.03.002 (2013).

81 Martiniello, G. Bitter sugarification: sugar frontier and contract farming in Uganda. Globalizations 18, 355-371, doi:10.1080/14747731.2020.1794564 (2021).

\section{Figures}

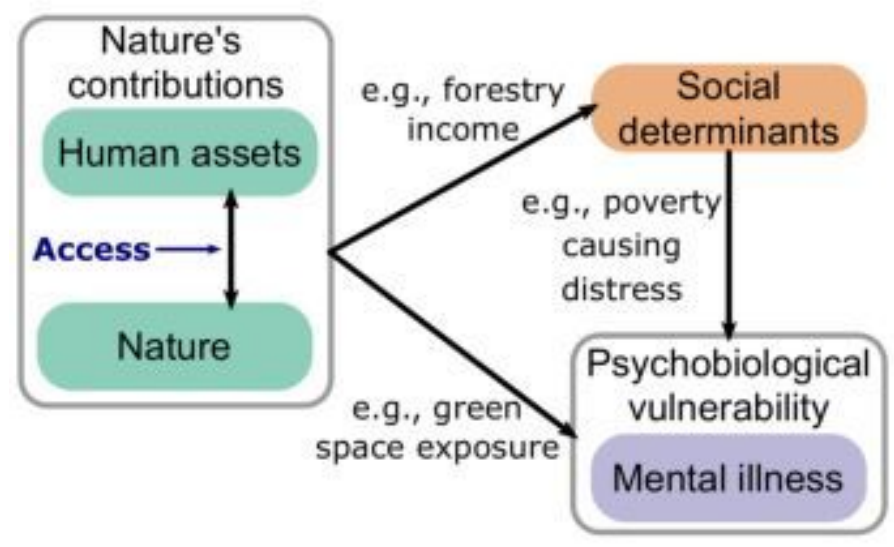

\section{Figure 1}

Illustrating how interactions between people and nature co-produce contributions that affect social determinants of mental illness, depending on an individual's psychobiological vulnerabilities (adapted from Pienkowski, et al. 14). Access is one factor that mediates the interaction between people and nature. 


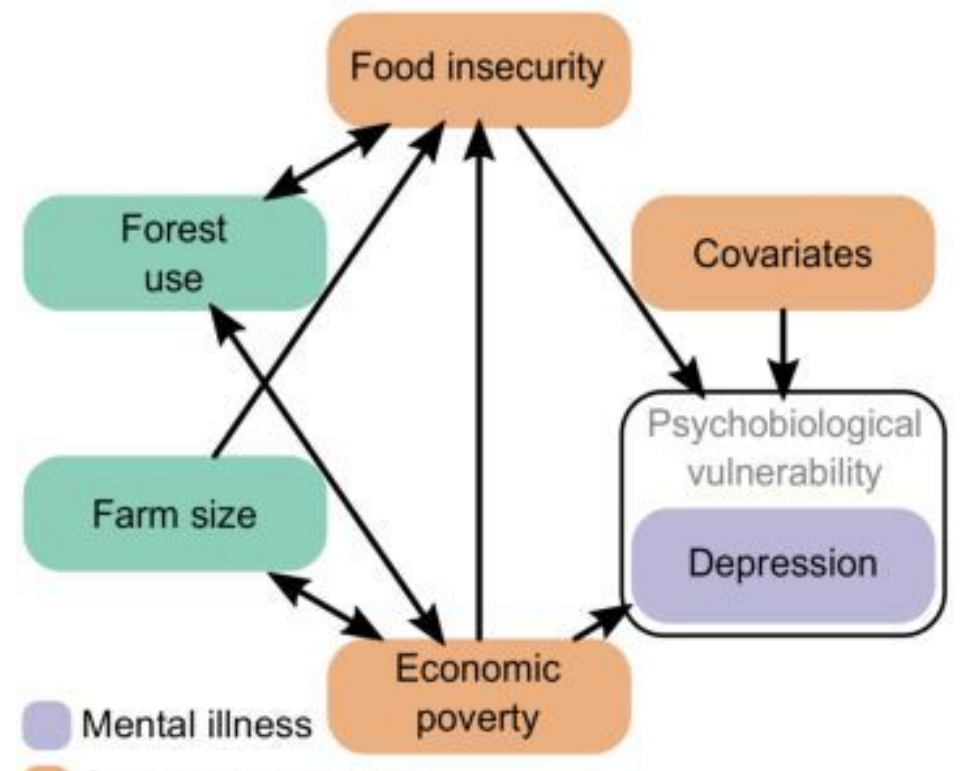

Social determinant

Proxies for forest and land use

\section{Figure 2}

An illustration of the hypothesised links between farm sizes and forest use (proxies for nature's contributions), food insecurity and depression (social determinants) and depression risk (mental illness) in our case study site. Single-headed arrows describe correlations, and bi-directional arrows describe covariance.

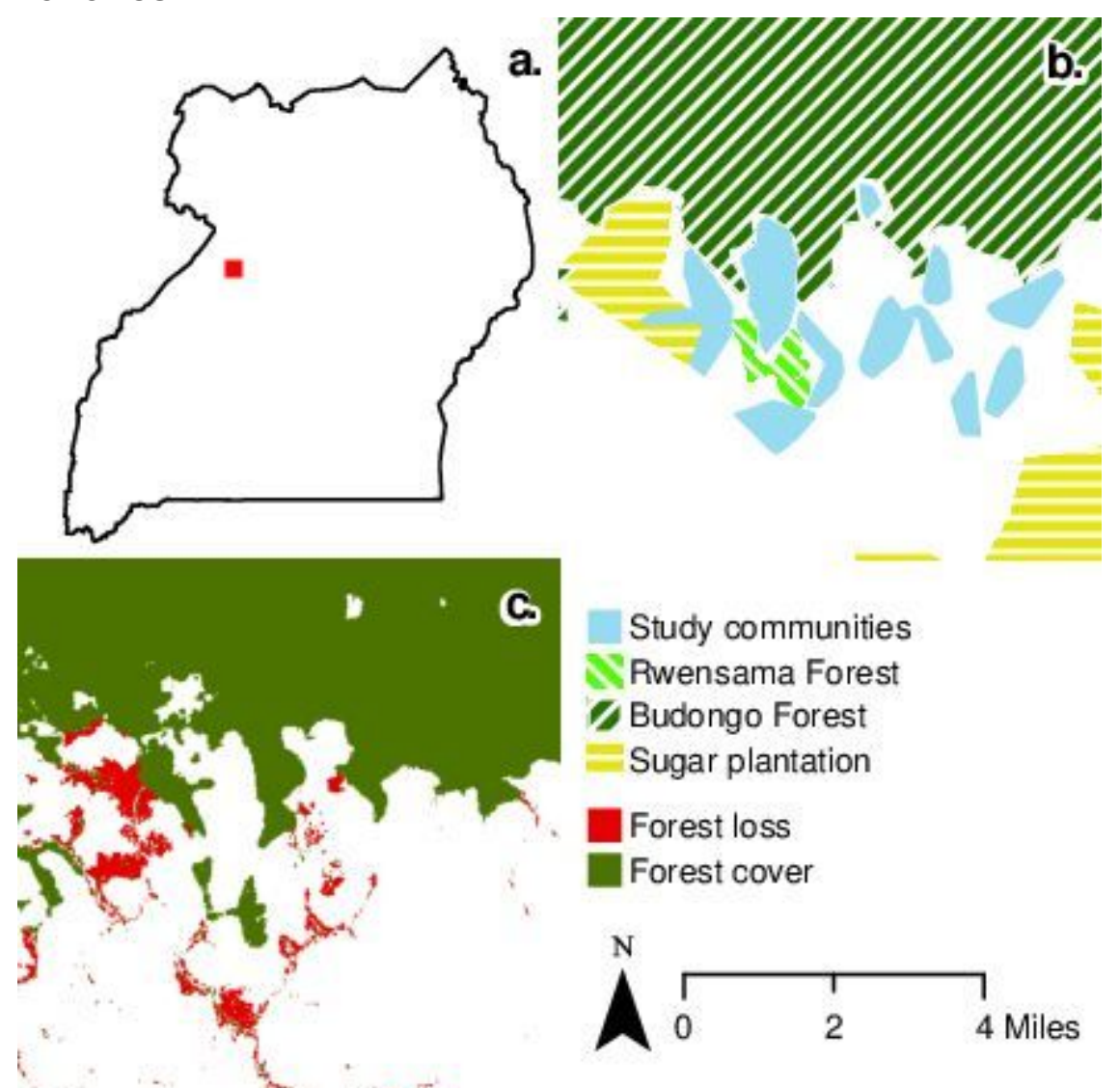




\section{Figure 3}

Maps describing the study area. Panel a. describes the location of the study site within Uganda. Panel b. describes the study area, including the 11 study communities, the Budongo and Rwensama Forest Reserves, and the indicative location of large-scale intensive sugarcane estates (adapted from34,47). Panel c. describes forest loss between 2000 and 2016 and forest cover (>75\% tree cover) in 2016 (adapted from48).

a.

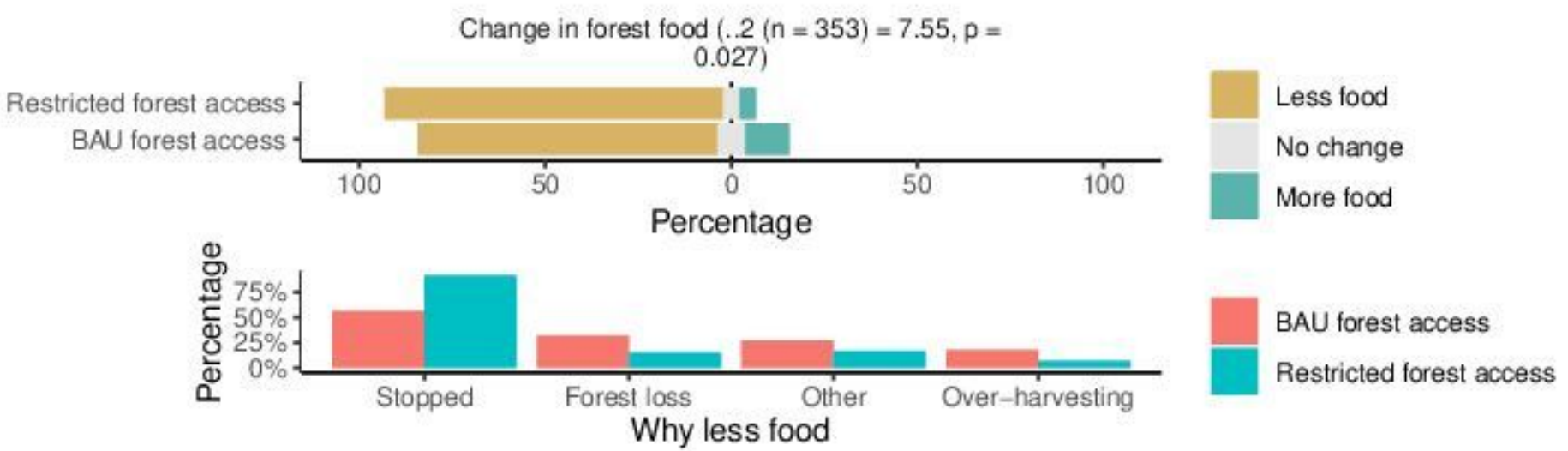

c.

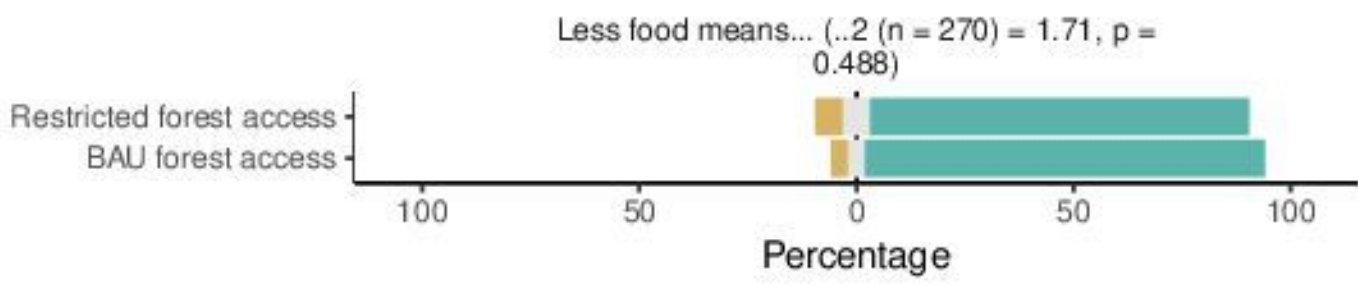

Less hunger No change More hunger

d.

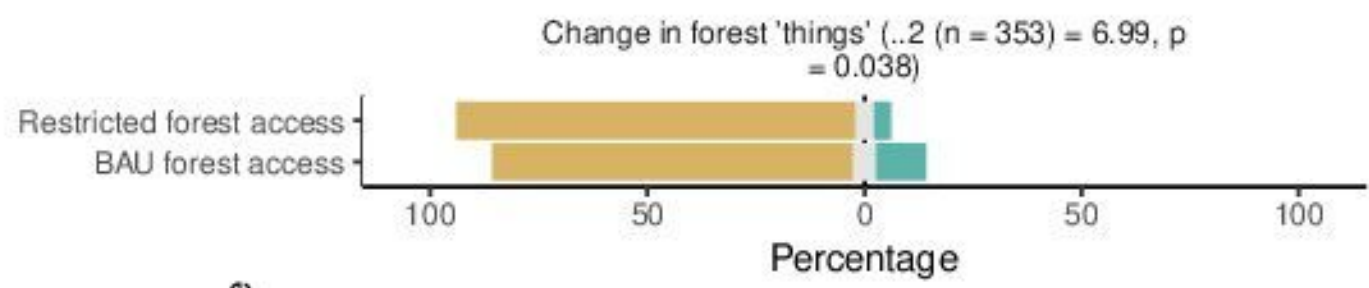

e.

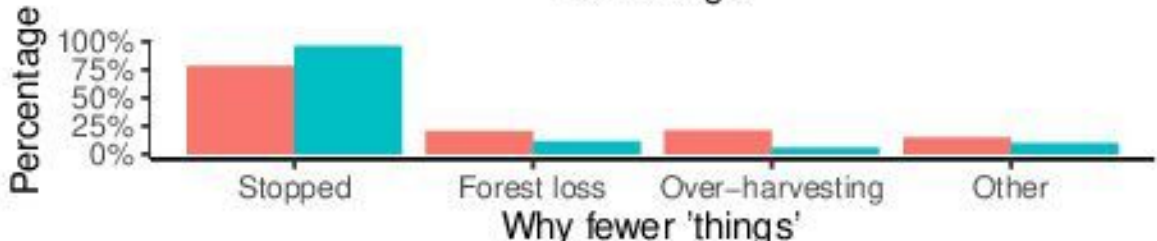

Fewer 'things' No change More 'things'

BAU forest access

Restricted forest access

f. Fewer 'things' means... $(.2$ ( $n=281)=3.00, p=$ 0.203 )

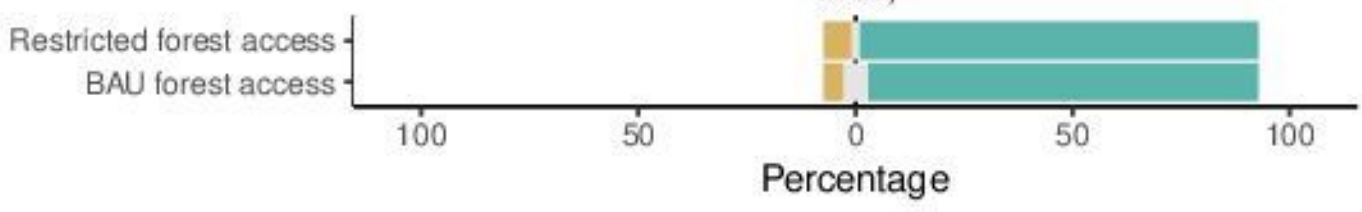

Less poverty No change More poverty

\section{Figure 4}

Scenario-based interview responses to two forest access scenarios. Panel a. describes expected changes in the amount of food from forests over the next decade, panel b. shows reported reasons for this decline, and panel c. illustrates expected consequences for household hunger (among forest users). Panel d. 
shows expected changes in the amount of income-generating 'things' from the forest, panel e. describes the reported reasons for this decline, and panel $\mathrm{f}$. displays the expected consequences for household poverty (among forest users). Key: BAU = business-as-usual.

a.

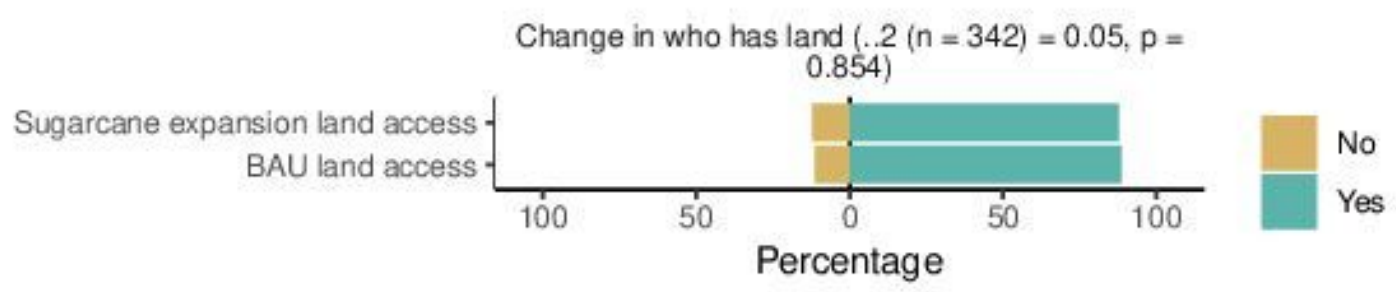

b.

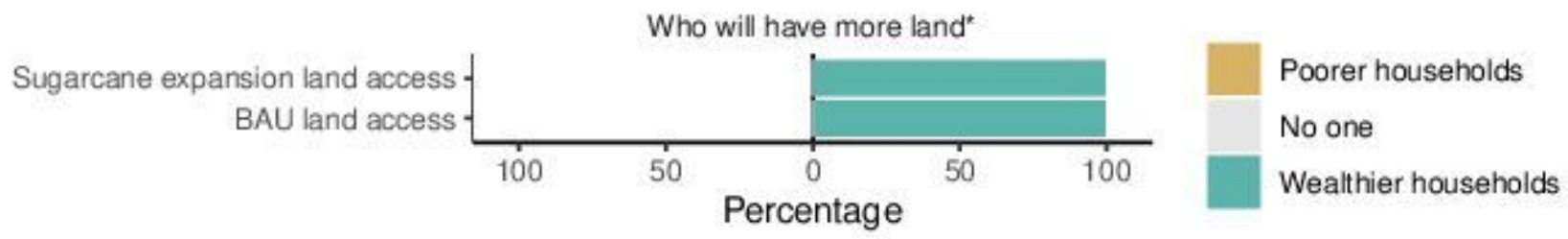

c. Who will have less land $(.2(n=278)=4.60, p=$ $0.058)$

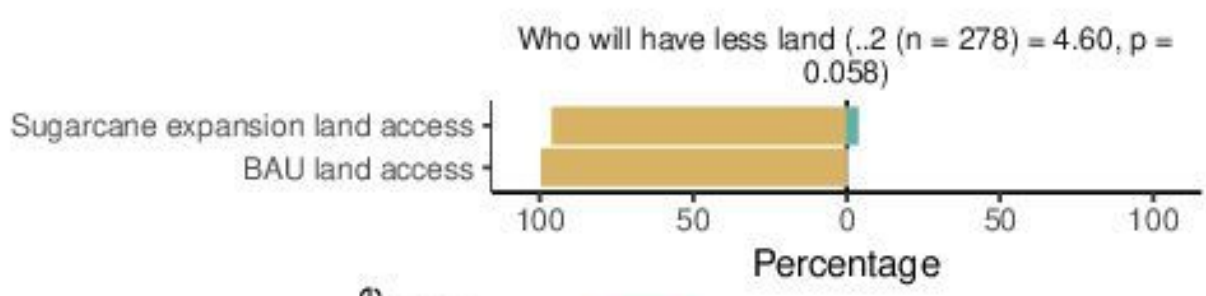

d.

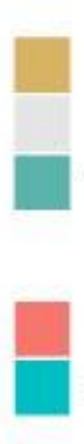

Poorer households No one

Wealthier households

$\mathrm{BAU}$ land access

Sugarcane expansion land access

e.

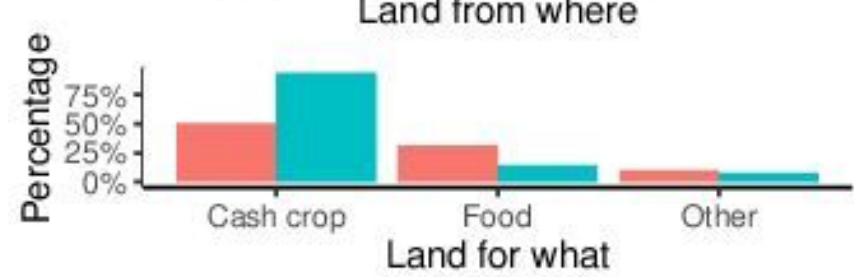

BAU land access

Sugarcane expansion land access

$\boldsymbol{f}$.

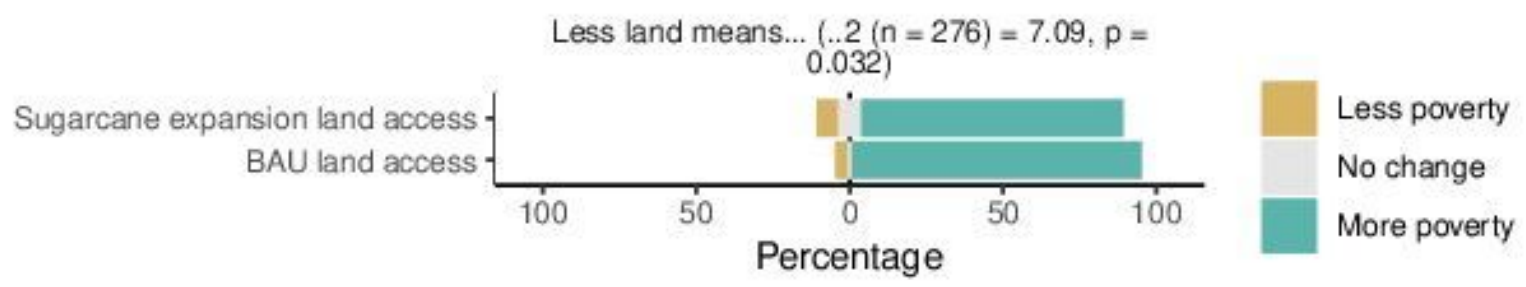

g.

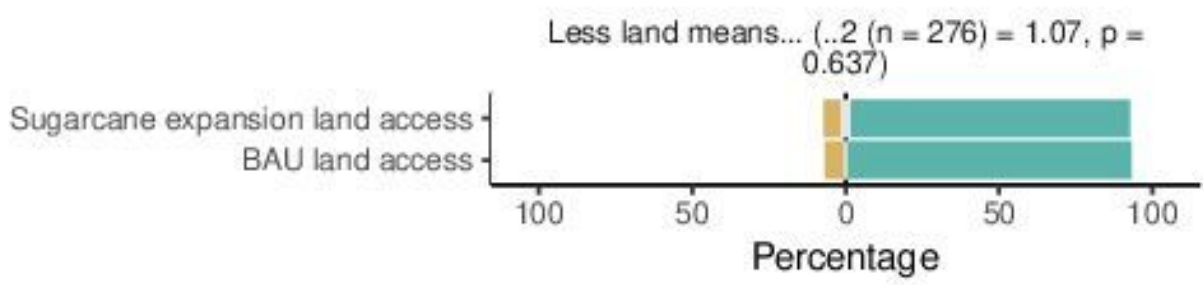

Less hunger

No change

More hunger

\section{Figure 5}

Scenario-based interview responses to two land access scenarios. Panel a. describes the proportion expecting changes in who has land over the next ten years, and panel b. and c. illustrates who is 
predicted to gain and lose land, respectively (among those expecting a change). Panel d. describes where this land is expected to come from, and panel e. displays what this land might be used for. Panel $f$. and $g$. illustrate the expected impacts of losing land on household poverty and hunger, respectively. *Where the chi-square test could not be formed because no respondents expected poorer households to gain land. Key: BAU = business-as-usual.

a.
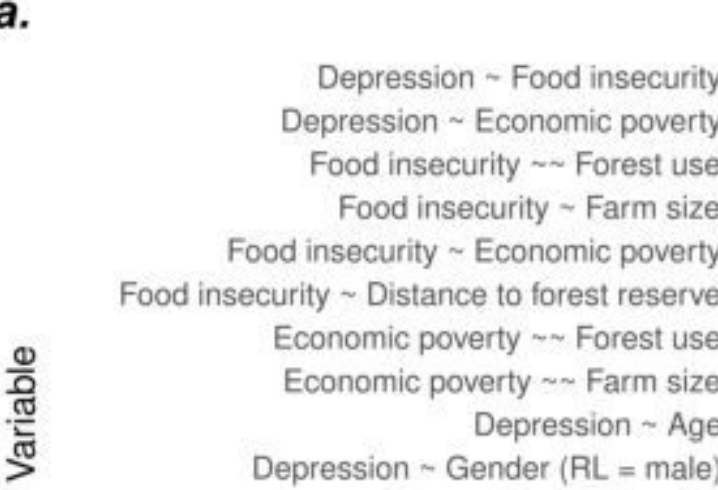

Depression Economic poverty

Food insecurity $\sim$ Forest use

Food insecurity $\sim$ Farm size

Food insecurity Economic poverty

Food insecurity $\sim$ Distance to forest reserve

Economic poverty $\sim \sim$ Forest use -

Economic poverty Farm size -

Depression Age -

Depression Gender $(\mathrm{RL}=$ male $)$

Depression Education

Depression Social support (family \& sig. other)

Depression Divorced or widow/er

Depression Never married -

Depression Health

Depression Alcohol consumption

Depression Daily smoker

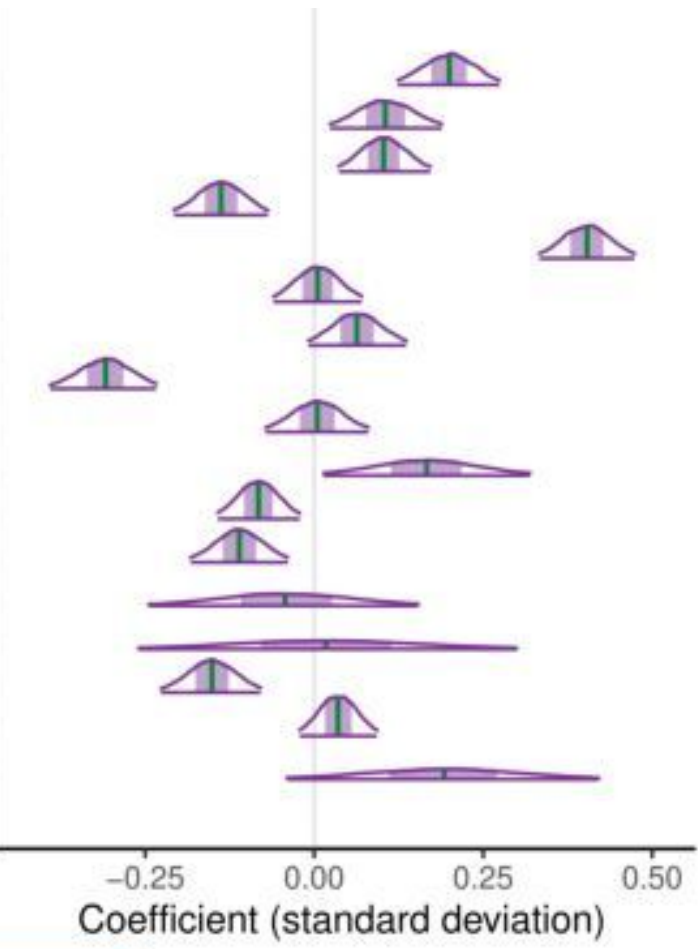

b.

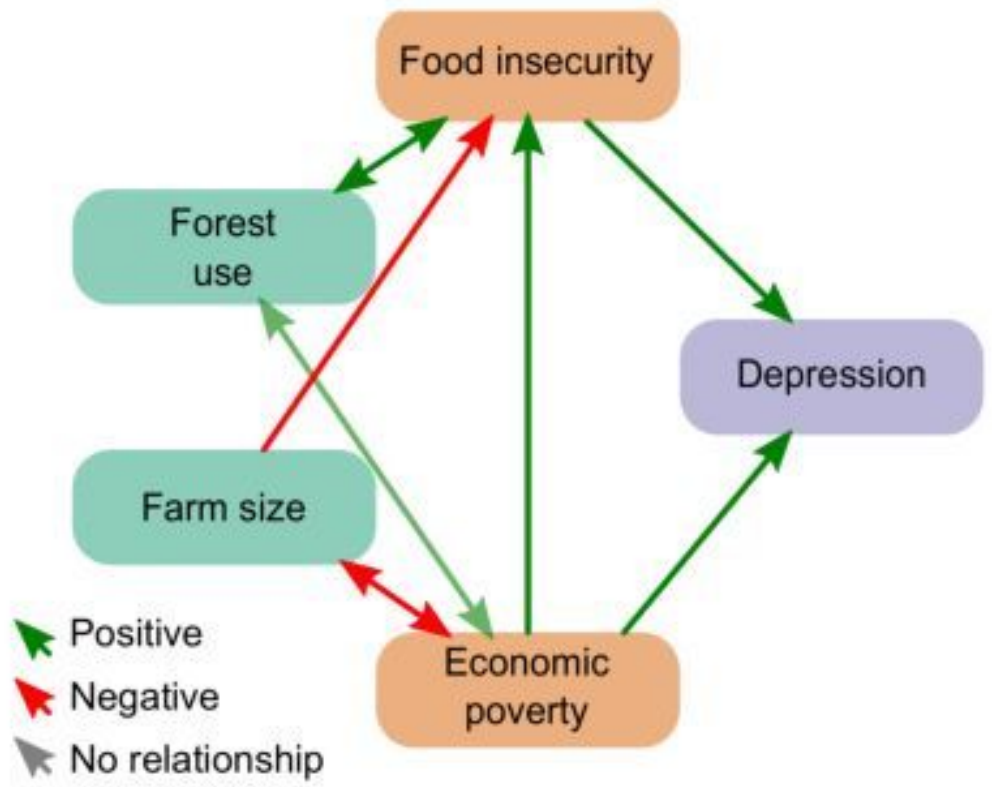

Figure 6

Bayesian structural equation modelling results. Panel a. describes the coefficient estimates from the Bayesian structural equation model using data from 695 respondents. The vertical green line represents the point estimate (median of the posterior distribution), the dark purple line represents the $95 \%$ credibility interval, and the shaded area represents the $50 \%$ credibility interval. The estimated associations between 
depressive symptom severity and the community dummy variables are not shown. Coefficient estimates are presented in standard deviations. Panel $b$. illustrates the direction of association between each variable (excluding covariates). The semi-opaque line indicates a marginally statistically uncertain association (as shown in Panel a.). Key: ' $\sim$ ' = regression, ' $\sim$ ' = co-variance, 'RL' = reference level.

\section{Supplementary Files}

This is a list of supplementary files associated with this preprint. Click to download.

- 8LandmanagementdepressionSlv1.docx 